intensive care unit after taking an overdose of an unknown quantity of oxazepam and chloral hydrate. On admission she was deeply unconscious with no eye opening, vocal response, or motor response to
pain. She had a weak gag reflex and slow, shallow respiration. Her pulse rate was 140 beats per minute and was in sinus rhythm. Her systolic blood pressure was $90 \mathrm{~mm} \mathrm{Hg}$. Initial management included endotracheal intubation, intermittent positive pressure ventilation, and gastric lavage.

One hour after admission she was still in a coma and needing ventilatory support so an intravenous dose of $0.5 \mathrm{mg}$ flumazenil was given slowly to antagonise the benzodiazepine component of her overdose. The patient became restless with an extensor response to pain and increased respiratory effort. Within seconds of the injection, however, she developed multifocal ventricular beats with short runs of ventricular tachycardia (figure). Two $50 \mathrm{mg}$ bolus injec-

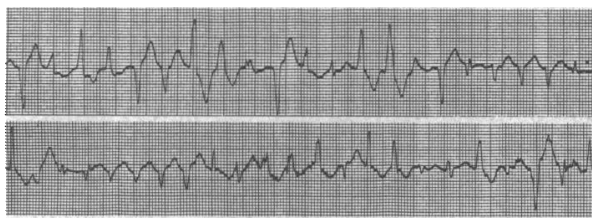

Electrocardiogram showing ventricular arrhythmia after the administration of flumazenil.

tions of lignocaine had no effect on the arrhythmia, which settled slowly over twenty minutes to occasional multifocal ventricular ectopic beats. During this time her level of consciousness returned to that immediately prior to the administration of flumazenil.

During the arrhythmia her heart rate was between 120 and 150 beats per minute and her systolic blood pressure was 110 to $120 \mathrm{~mm} \mathrm{Hg}$. Biochemical results when the flumazenil was given were sodium 143 $\mathrm{mmol} / 1$, potassium $4.2 \mathrm{mmol} / 1$, glucose $8.0 \mathrm{mmol} / 1$, arterial oxygen pressure $23 \mathrm{kPa}, \mathrm{pH} 7 \cdot 39$, arterial carbon dioxide pressure $4.3 \mathrm{kPa}$, and bicarbonate $19 \mathrm{mmol} / \mathrm{l}$.

The patient was extubated 20 hours after admission by which time her electrocardiogram was normal. Further questioning disclosed that she had a nine year history of physical dependancy on benzodiazepines and had developed insomnia, anxiety, and phobias on attempted withdrawal.

Flumazenil is a competitive antagonist of benzodiazepines. It may be given after overdose to decrease the time during which mechanical ventilation is needed, shorten the stay in an intensive care unit, and allow communication with the patient. Potential disadvantages include the possibility of withdrawal states in patients dependent on benzodiazepines and the potential for resedation because of its short half life $(60$ minutes) compared with sedative benzodiazepines.

In this case the rhythm disturbance was similar to that reported from chloral hydrate overdose, ${ }^{23}$ although its precipitation by flumazenil may have occurred through at least two mechanisms. Firstly, the direct effect of chloral hydrate on the heart may have been exaggerated by the reversal of the dampening effect of benzodiazepines on sympathetic nervous system activity. ${ }^{4}$ Secondly, the patient was physically dependent on benzodiazepines and may have suffered an acute withdrawal reaction on administration of the antagonist. This may have caused enhanced sympathetic activity, although arrhythmias are not characteristic of benzodiazepine withdrawal

In this patient the rapid clearance of flumazenil was an advantage because the cardiac effects wore off as she became resedated. $\beta$ Adrenergic blockage might have been a more appropriate antiarrhythmic treatment than lignocaine. It has been shown to be successful in treating chloral hydrate cardiotoxicity and would have reduced the sympathetic effects on the heart caused by the benzodiazepine withdrawal or the presence of an endotracheal tube. An alternative approach may have been to give additional benzodiazepine to overcome the activity of the flumazenil.

The manufacturers of the drug (Roche, Basle) have one previous unpublished report of an unspecified cardiac arrhythmia occurring after flumazenil reversal of a combined oxazepam and chloral hydrate overdose. We urge caution in the use of flumazenil to reverse the benzodiazepine component of mixed drug overdose when cardiotoxic drugs such as chloral hydrate may have been taken or the patient's state of dependency on benzodiazepines is not known.

1 Ashton $\mathrm{CH}$. Benzodiazepine overdose: are specific antagonists useful? Br Med F 1985;290:805-6.

Wiseman HM Hampel G. Cardiac arrhythmias due to chloral hydrate poisoning. BrMed $\mathcal{F}$ 1978;2:960.

DiGiovanni AC. Reversal of chloral hydrateassociated arrhythmi by a beta-adrenergic blocking agent. Anesthesiology 1969;31:93. 4 Marty J, Gauzit R, Lefevre P, et al. Effects of diazepam and midazolam on baroreflex control of heart rate and on sympathetic activity in humans. Anesth Analg 1986;65:113-9. Smith DE, Wesson DR. Benzodiazepine dependency syndromes. In: Smith DE, Wesson DR, eds. The benzodiazepines, curren standards for medical practice. Lancaster: MTP Press Ltd, 1985:235-48.

\section{Psychiatric symptoms associated with carbamazepine}

Dr G Mathew (Cell Barnes Hospital, St Albans, Herts AL4 0RG) writes: A 24 year old man with epilepsy and mild mental handicap whose treatment was changed in January 1987 from sodium valproate to carbamazepine presented with mood swings, episodic aggressive outbursts, and thought disorder. He talked of hearing sounds in a different language and was convinced that inanimate objects altered his voice. He expressed paranoid ideas and his affect was one of fear and hostility. His sensorium remained intact and serum carbamazepine concentrations did not show toxicity. In June 1987 carbamazepine was tapered off and sodium valproate reintroduced. A week after stopping carbamazepine he showed a pronounced sustained improvement in his mental state and behaviour.

A 5 year old girl with epilepsy was given carbamazepine. She developed a severe phobia of water. This disappeared on stopping the drug.

Carbamazepine is recognised to have psychotropic effects and reported symptoms include schizophreniform psychosis, explosiveness with rage and confusion, fear of being poisoned, and severe behaviour disorder. In a case reported from Spain delusions occurred during treatment with carbamazepine and disappeared on its withdrawal only to reappear on challenge with the drug. ${ }^{2}$ Neither the Committee on Safety of Medicines nor the manufacturer knows of any other cases of psychosis caused by carbamazepine.

Psychotic symptoms may occur in anticonvulsant toxicity; however, brain damaged or mentally impaired people are sensitive to marginally raised concentrations of anticonvulsant drugs. ${ }^{3}$ Doctors need to be aware that psychiatric symptoms induced by carbamazepine at non-toxic concentrations may occur as idiosyncratic reactions in some people.

Dalby MA. Anti-epileptic and psychotropic effect of carbamazepine in the treatment of Psychomotor Epilepsy. Epilepsia 1971;12:325-34

2 Mastach L. Un caso de psicosis delirante en relacion con un tratamiento

3 Franks RD, Richter AJ. Schizophrenia-like psychosis associated with anti-convulsant toxicity. Am J Psychiatry 1979;136: 7:973-4.

\section{Benzydamine oral rinse and rash}

Mrs Margaret TURner (Department of Pharmacy) and Dr ROGER LAITT (Department of Surgery, Hope Hospital, Salford M6 8HD) write: A 21 year old man with Crohn's disease developed severe painful mouth ulceration after seven days of ventilation after an emergency laparotomy for a perforated colon Benzydamine oral rinse (Difflam, Riker) was started at a dose of $10 \mathrm{ml}$ four times daily. Within three days the patient had a maculopapular, morbilliform rash over the trunk and limbs. The rash spread progressively and intensified over the next three days. The mouthwash and ranitidine, which had been administered concurrently, were discontinued. Over the following 48 hours the rash receded, and ranitidine was restarted with no adverse sequelae. There have been at least 40 reports to the Committee on Safety of Medicines of skin reactions associated with topical benzydamine cream, including seven of photosensitivity. ${ }^{1}$ The manufacturer has also received a report of a rash around the mouth after use of the oral rinse. The widespread rash described here has not been previously reported in patients using the oral rinse. The preparation is cosmetically coloured with quinolone yellow and patent blue $\mathrm{V}$. The proposed hypersensitivity reaction may be due to systemic absorption of the drug or the colouring agents.

1 Anonymous. Difflam-a topical NSAID. Drug and Therapuetics Bulletin 1986;24:19-20.

\section{Severe toxic erythema caused by diltiazem}

Drs Riadh A Wakeel, Michael P Gavin, and MARTIN KEEFE (Department of Dermatology, Stobhil General Hospital, Glasgow G21 3UW) write: Diltiazem is a calcium antagonist used to treat angina. Severe cutaneous reactions have been reported, ${ }^{12}$ but this is not clear from the datasheet or the British National Formulary, ${ }^{3}$ which simply list rashes among side effects of the drug. We describe a case of severe toxic erythema which followed treatment with diltiazem.

In August 1987 a 48 year old woman with a three month history of angina was admitted as an emergency because of sudden onset of a generalised rash. Her angina had originally been treated with atenolol $50 \mathrm{mg}$ daily and nifedipine $10 \mathrm{mg}$ three times a day. Ten days before admission she had had severe chest pain and nifedipine had been replaced with diltiazem $60 \mathrm{mg}$ three times a day. On examination the skin showed a confluent annular eruption with target lesions (figure)

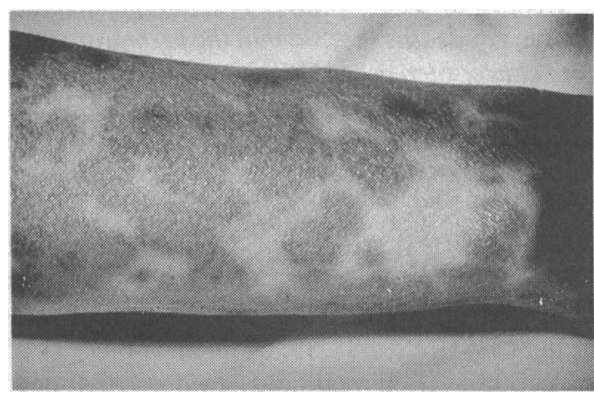

Confluent annular eruption on the arm with target lesions.

symmetrically distributed over the face, neck, trunk and limbs. The hands and feet were spared. There was no blistering and no mucosal lesions. Histological examination of a lesion on the chest showed nonspecific subacute dermatitis. The histological and clinical appearances together were consistent with a diagnosis of toxic erythema. Other causes ${ }^{4}$ were excluded. Treatment consisted of replacing diltiazem with isosorbide mononitrate and a short course of oral prednisolone. The rash rapidly resolved with desquamation of skin in the affected areas. The patient was discharged after five days.

The time course and resolution after withdrawal of diltiazem are strongly suggestive of a drug eruption. By November 1987 the Committee on the Safety of Medicines had received 158 reports of skin reactions to diltiazem, including two severe reactions (exfoliative dermatitis and toxic epidermal necrolysis). The manufacturers are aware of four severe reactions. Clinicians should be alerted to this severe adverse reaction to diltiazem. Patients with angina are often taking several drugs and withdrawal of medication can be hazardous. It is essential therefore that adverse reactions should be clearly documented to allow selective drug withdrawal where necessary.

1 Larvijsen APM, Von Dijike C, Vermeer BJ. Diltiazem associated exfoliative dermatitis in a patient with psoriasis. Acta Derm Venereol (Stockh) 1986;66:536-8.

2 Quigley MA, White KL, McGraw BF. Interpretation and application of world-wide safety data on diltiazem. Acta Pharm Toxicol 1985;57 (suppl 11):61-73.

3 British Medical Association and Pharmaceutical Society of Great Britain. British national formulary. Number 13. London: BMA and Pharmaceutical Press, 1987:96.

Champion RH. Erythema. In: Rook A, Wilkinson DH, Ebling FJG, Champion RH, Burton JL, eds. Textbook of dermatology. 4th ed. Vol 2. Oxford: Blackwell Scientific, 1986:1084. 